\title{
Attitudes of general dental practitioners towards biopsy procedures.
}

\author{
Vinita Murgod ${ }^{1}$, Punnya. V Angadi ${ }^{2}$, Seema Hallikerimath ${ }^{3}$, Alka D Kale ${ }^{4}$, Mamta Hebbal ${ }^{5}$ \\ ${ }^{1}$ MDS, Post graduate student, Department of Oral Pathology and Microbiology, KLEVK Institute of Dental Sciences and Hospi- \\ tal, Belgaum, Karnataka, India. \\ ${ }^{2}$ MDS, DNB, Reader, Department of Oral Pathology and Microbiology, KLEVK Institute of Dental Sciences and Hospital, \\ Belgaum, Karnataka, India. \\ ${ }^{3}$ MDS, Professor \& Head, Department of Oral Pathology and Microbiology, KLEVK Institute of Dental Sciences and Hospital, \\ Belgaum, Karnataka, India. \\ ${ }^{4}$ MDS, Professor, Department of Oral Pathology and Microbiology, KLEVK Institute of Dental Sciences and Hospital, Belgaum, \\ Karnataka, India. \\ ${ }^{5}$ MDS, Reader, Department of Community Dentistry, KLEVK Institute of Dental Sciences and Hospital, Belgaum, Karnataka, \\ India.
}

Correspondence:

KLEVK Institute of Dental Sciences and Hospital,

Belgaum-590010,Karnataka- INDIA.

E-mail: punnya_angadi@rediffmail.com

Murgod V, Angadi PV, Hallikerimath S, Kale AD, Hebbal M. Attitudes of general dental practitioners towards biopsy procedures. J Clin Exp Dent. 2011;3(5):e418-23.

http://www.medicinaoral.com/odo/volumenes/v3i5/jcedv3i5p418.pdf http://www.medicinaoral.com/odo/indice.htm

(CIF. B $96689336-$ eISSN: 1989-5488

eMail: jced@jced.es

\begin{abstract}
Objectives: A dentist is required to detect and recognise oral lesions and inform the patient accordingly by providing a diagnosis and adequate treatment plan. Biopsy serves as an important aid in achieving this goal; however, its use is not so widespread in general dental practice. The objective of the present study was to explore the attitudes of general dental practitioners in Belgaum city towards biopsy for diagnosis of oral lesions.

Material and methods: A self designed questionnaire was administered to 74 general dental practitioners in Belgaum city, in the southern region of India, consisting of several items addressing the socio-demographic and professional aspects and their attitudes towards oral biopsy procedures.

Results: The response rate was exceptionally high i.e. $90.54 \%$. All the dentists felt that biopsy was an important tool in diagnosis of oral lesions but many still did not venture to undertake it on their own and preferred referring it to a specialist or higher care centre. This was mainly due to lack of experience and patient factors. There were also conflicting results regarding referral diagnostic pathology services and preservation of the biopsy specimens.

Conclusion: This emphasizes the need for higher levels of importance to be placed on this aspect in undergraduate and postgraduate dental curriculum. Organisation of specific training or continuing dental education programmes to enhance their practical skills could aid in increasing the utility of this important tool in diagnosis of oral lesions.
\end{abstract}

Key Words: Biopsy, attitudes, general dental practitioners, curriculum, continued dental education. 


\section{Introduction}

The word biopsy originates from the Greek term bios (life) and opsis (vision): meaning vision of life (1). In routine practice, the clinical diagnosis of oral lesions frequently must be confirmed by different procedures, among which oral biopsy constitutes an important tool by establishing the histologic characteristics. At times, it could be the only way to diagnose some oral lesions $(2,3)$. It must be highlighted that oral biopsy is not only limited to diagnosis, but is also greatly useful to determine the nature of the lesions i.e. benign /malignant and for designing effective treatment strategies. The primary indications of oral biopsy include premalignant lesions like leukoplakia, erythroplakia etc. and for detection of malignancy. However, it can also be applied for benign lesions like mucocele, fibrous hyperplasias, etc., for vesiculobullous lesions like pemphigus, pemphigoid, lichen planus as well as for bony lesions like cysts and periapical lesions among others (2). Additionally, it has irrefutable medicolegal value (1).

The main types of biopsies include: Excisional biopsy which is undertaken to remove small benign lesions, incisional biopsy; done for large or suspicious lesions to determine the diagnosis while fine needle aspiration biopsy can be applied for diagnosis of cysts, lymph node lesions and salivary gland disorders (4).

The tissue obtained after biopsy needs to be fixed in appropriate solution i.e. in 10\% neutral buffered formalin in adequate volume, atleast ten times that of the specimen and then sent for histopathological evaluation. Additional information, that the clinician needs to convey to the pathologist along with the specimen includes the demographic data, the history of the lesion along with the detailed medical and drug history, the clinical appearance, the site of biopsy and the clinician's provisional diagnosis (5).

In general, the dentist is required to detect and recognise oral lesions and inform the patient accordingly by providing a diagnosis and adequate treatment plan. Biopsy serves as an important aid in achieving this goal. Dentists therefore, must not only know where, when and how to perform biopsy, the preservation of tissue thereof but also is able to manage the subsequent report $(6,7)$. It is well within the scope of general dental practitioners (GDPs) to carry out small incisional and excisional biopsies rather than refer them $(8,9)$. In spite of the range of benefits of performing biopsy, it is observed that practice of oral biopsy is not so widespread in dental practice (1, 10). This could be attributed to several reasons like fear of medicolegal complication, unfamiliarity with biopsy technique, misconception of it being a predominant specialist procedure etc. It seems paradoxical that GDPs will render a patient edentulous yet hesitate to remove a few millimetres of soft tissue (6). The present study aims to explore the attitudes of general dental practitioners in
Belgaum city towards oral biopsy for diagnosis of oral lesions.

\section{Material and methods}

Belgaum is the third largest city in the northwest of Karnataka state with a population of approximately five lakhs. The study focused on general dental practitioners with an undergraduate qualification of Bachelor of dental surgery and excluded all professionals exclusively dedicated to some specialty. It included a self designed questionnaire that consisted of twenty two items with eight open and fourteen close ended questions. It included two item blocks; one addressed the socio-demographic and professional aspects, while the second explored the attitudes towards oral biopsy which included the importance, knowledge and practice regarding lesions requiring biopsy, biopsy methods, diagnostic pathology referral and preservation of specimens. A pilot study was carried out with five dentists selected due to their accessibility and proximity to the investigational team. Changes in the questions were then made accordingly and the pilot study samples were deleted from the final study sample. The list of 128 GDPs in the city was obtained from the register of Belgaum branch of Indian Dental Association. Among them excluding the specialists, a total of 74 GDPs were approached. After obtaining the ethical clearance from the institutional review board; the questionnaires were self-administered by the researcher. Following which; the purpose of the study was explained to the GDPs and verbal consent was obtained and the questionnaire was given. Results were tabulated and percentage was then calculated.

\section{Results}

Of the 74 private dentists that were approached with the questionnaire; there were 67 GDP who answered the questionnaire which included $43(64.18 \%)$ male and 24 $(35.82 \%)$ female dentists. The mean age of the dentists was around 32.75 years. By gender, the mean age was for females (31.37 years) and for male (33.52years). With regards to their professional setting, 44 were in solo practice while 18 practiced as a group. Among them, 55 dentists had consultants of various specialities visiting their clinic.

All the GDPs (100\%) said it is very important to perform biopsies for diagnosis of oral lesions. On asking what lesions require biopsy, according to their knowledge, $15(22.38 \%)$ thought that it should be done for all benign, premalignant, malignant and cystic lesions, while $12(17.9 \%)$ felt it should be used for only premalignant and malignant lesions. Few 9 (13.4\%) felt it needs to be used only for premalignant lesions while 8 (11.94\%) thought it is utilised only for diagnosis of malignant lesions. Three $(4.48 \%)$ believed that biopsy is done only for benign lesions (Table 1). 


\begin{tabular}{|c|c|c|}
\hline Lesions & $\begin{array}{l}\text { Which lesions } \\
\text { require biopsy } \\
\text { according to } \\
\text { you? }\end{array}$ & $\begin{array}{l}\text { Which } \\
\text { lesions } \\
\text { have you } \\
\text { come across } \\
\text { in your } \\
\text { practice? }\end{array}$ \\
\hline All & $22.39 \%$ & $8.96 \%$ \\
\hline Premalignant lesions only & $13.43 \%$ & $10.45 \%$ \\
\hline Benign lesions only & $4.48 \%$ & $7.46 \%$ \\
\hline Malignant lesions only & $11.94 \%$ & $8.96 \%$ \\
\hline Cysts only & - & $2.99 \%$ \\
\hline Benign and malignant & $1.49 \%$ & $4.48 \%$ \\
\hline Benign and premalignant & $1.49 \%$ & - \\
\hline Premalignant and malignant & $17.91 \%$ & - \\
\hline Malignant and cysts & $5.97 \%$ & $7.46 \%$ \\
\hline Benign and cysts & - & $7.46 \%$ \\
\hline Premalignant and cysts & - & $5.97 \%$ \\
\hline Premalignant and malignant & - & \\
\hline Benign, premalignant and cysts & $2.99 \%$ & $5.97 \%$ \\
\hline $\begin{array}{l}\text { Benign, premalignant and ma- } \\
\text { lignant }\end{array}$ & $4.48 \%$ & $7.46 \%$ \\
\hline $\begin{array}{l}\text { Premalignant, malignant and } \\
\text { cysts }\end{array}$ & $4.48 \%$ & $7.46 \%$ \\
\hline Benign, malignant and cysts & $4.48 \%$ & $7.46 \%$ \\
\hline Malignant and any other specify & $1.49 \%$ & - \\
\hline $\begin{array}{l}\text { Premalignant, malignant, cysts } \\
\text { and any other }\end{array}$ & $1.49 \%$ & - \\
\hline $\begin{array}{l}\text { Benign, premalignant, malig- } \\
\text { nant, cysts and any other }\end{array}$ & $1.49 \%$ & - \\
\hline Not encountered & - & $7.46 \%$ \\
\hline
\end{tabular}

Table 1. General dental practitioners' knowledge regarding the lesions requiring biopsy and their personal experience for the same

Most dentists 46 (68.6\%) said that they come across lesions requiring biopsy at least once a year while $11.94 \%$ said that they come across such lesions once a month and $3 \%$ once a week. Some $(10.45 \%)$ said that they come across such lesions only once in 5 years. On asking about the types of lesions requiring biopsy they have come across in their practice, it was seen that $19.41 \%$ have come across premalignant and malignant lesions. The details are in the Table 1.

It was evident that most GDPs either called a specialist for biopsy $(34.33 \%)$ or referred them to a higher centre $(31.34 \%)$. Only a small percentage $(14.93 \%)$ said that they perform the biopsies themselves. As to how often they refer/ perform biopsies, most answered (68.65\%) that they did so at least once a year (Table 2 and 3).

On the subject of what type of biopsy methods, they were acquainted with; $59.7 \%$ dentists were aware of all the types of biopsy methods, mentioned in the questionnaire i.e. incisional, excisional and fine needle aspiration (FNA) biopsy while $14.93 \%$ dentists knew only about incisional biopsy, 7.46\% knew about incisional and excisional and the rest knew about one or the other (Table 4).

Further, on asking whether they sent it for analysis after removal, $85.07 \%$ responded among which $59.7 \%$ said they send the specimens for analysis and always. Around $14.92 \%$ send it only when required while $10.45 \%$ send it only sometimes (Table 2).

The questionnaire sought opinion of the dentists regarding preservation of the specimen after removal, 36 (53.73\%) practitioners, alleged that specimens need to be sent in formalin; while $20(29.85 \%)$ believed that it can be sent in saline and $11.94 \%$ said that specimens need to be sent in alcohol; while $2.98 \%$ did not know at all regarding the preservation (Table 4). On asking, about the method of preservation used in their clinic, 33(49.25\%) said they preserved in formalin while $21(31.34 \%)$ used saline and $13.42 \%$ used alcohol. $1.49 \%$ dentists sent it either in saline or formalin based on whichever is accessible at the moment (Table 3 ).

The common reasons quoted for not performing biopsy were patients don't agree (23.88\%) and due to the lack of experience and skills in performing biopsy (22.39\%). $14.92 \%$ reasoned that they lack instruments required for biopsy and $2.98 \%$ answered due to lack of nearby pathology laboratory service.

95.5\% dentists feel a need to update knowledge regarding lesions and biopsy procedures and $92.54 \%$ respon-

\begin{tabular}{l|l|l|l}
\hline \multicolumn{2}{l|}{ For lesions requiring biopsy what do you do? } & \multicolumn{2}{l|}{ After removal do you send for analysis? } \\
\hline Options & Response & Options & Response \\
\hline Call a specialist & $34.32 \%$ & Send for analysis and always & $59.7 \%$ \\
\hline Refer to a higher centre & $31.34 \%$ & $\begin{array}{l}\text { Send it for analysis only when re- } \\
\text { quired }\end{array}$ & $14.93 \%$ \\
\hline Perform biopsy on their own & $14.93 \%$ & $\begin{array}{l}\text { Send it for analysis only someti- } \\
\text { mes }\end{array}$ & $10.45 \%$ \\
\hline $\begin{array}{l}\text { Either call a specialist or refer to a higher } \\
\text { centre }\end{array}$ & $4.48 \%$ & No response & $14.92 \%$ \\
\hline Any other & $14.92 \%$ & & \\
\hline
\end{tabular}

Table 2. General dental practitioners' practices for the lesions requiring biopsy 


\begin{tabular}{l|l|l|l|l|l|}
\hline $\begin{array}{l}\text { How often do you come across an oral le- } \\
\text { sion requiring biopsy? }\end{array}$ & \multicolumn{2}{l|}{ Method of biopsy used } & \multicolumn{2}{l}{$\begin{array}{l}\text { Method for preservation of specimen used } \\
\text { in your clinic. }\end{array}$} \\
\hline At least once in 5years & $10.45 \%$ & Incisional biopsy & $22.39 \%$ & Saline & $31.34 \%$ \\
\hline At least once in a year & $68.65 \%$ & Excisional biopsy & $23.88 \%$ & Alcohol & $13.43 \%$ \\
\hline At least once in a month & $11.94 \%$ & FNA & $10.45 \%$ & Formalin & $49.26 \%$ \\
\hline At least once in a week & $2.99 \%$ & $\begin{array}{l}\text { Incisional and exci- } \\
\text { sional }\end{array}$ & $5.97 \%$ & No response & $5.97 \%$ \\
\hline Any other specify & $5.97 \%$ & Incisional and FNA & $7.46 \%$ & & \\
\hline & & All three & $10.45 \%$ & & \\
\hline
\end{tabular}

FNA : Fine needle aspiration

Table 3. General dental practitioners' practices towards lesions requiring biopsy

\begin{tabular}{l|l|}
\hline Which types are you of biopsy methods aware of? & How do you think, the specimen should be preserved be-
\end{tabular} \begin{tabular}{|l|l} 
& fore sending for analysis?
\end{tabular}

\begin{tabular}{l|l|l|l}
\hline Incisional biopsy only & $14.93 \%$ & Saline & $29.85 \%$ \\
\hline Excisional biopsy only & $5.96 \%$ & Alcohol & $11.94 \%$ \\
\hline Fine needle aspiration only & $2.99 \%$ & Formalin & $53.73 \%$ \\
\hline Incisional and excisional & $7.46 \%$ & Saline and Formalin & $1.49 \%$ \\
\hline Incisional and fine needle aspiration & $4.48 \%$ & Any other & $2.99 \%$ \\
\hline Excisional and fine needle aspiration & $4.48 \%$ & & \\
\hline Incisional, excisional and FNA & $59.7 \%$ & & \\
\hline
\end{tabular}

FNA : Fine needle aspiration

Table 4. General dental practitioners' knowledge of biopsy procedures and preservation of the specimens.

ded that they update their knowledge regarding the same by various methods (Table 5).

\section{Discussion}

Boyle (11) said rightfully in 1955; that an individual's qualifications have little to do with ability to perform biopsy. Biopsy is of paramount importance as it is strongly related to diagnosis and detection of oral cancer (12). Although most dentists prefer to refer biopsy cases to specialist or higher centre, most believe that routine biopsies are well within the scope of a GDP as this would provide direct access to prompt management. The present study thus sought to evaluate the attitudes of GDPs with an undergraduate degree in dentistry in performing biopsy for diagnosis of oral lesions. On literature review, there have been no similar studies reported especially from India.

The response rate was exceptionally high (90.54\%), probably because the questionnaires were self administered compared to questionnaire studies conducted by means

\begin{tabular}{l|l|l|l|l|l|}
\hline $\begin{array}{l}\text { Do you feel there is a need to upda- } \\
\text { te your knowledge regarding lesions } \\
\text { and biopsy procedures? }\end{array}$ & $\begin{array}{l}\text { Do you update yourself } \\
\text { regarding the same? }\end{array}$ & \multicolumn{2}{l}{ If yes, how do you update yourself? } \\
\hline Yes & $95.52 \%$ & Yes & $92.54 \%$ & Journals & $31.34 \%$ \\
\hline No & $4.48 \%$ & No & $7.46 \%$ & Internet & $11.94 \%$ \\
\hline & & & & Conferences & $4.48 \%$ \\
\hline & & & Journals and internet & $28.36 \%$ \\
\hline & & & & Internet and conferences & $2.99 \%$ \\
\hline & & & Journals and conferences & $2.99 \%$ \\
\hline & & & Journals, internet and conferences & $7.46 \%$ \\
\hline & & & $\begin{array}{l}\text { Internet and other sources } \\
\text { (workshops, group practice, CDE programmes etc) }\end{array}$ & $2.99 \%$ \\
\hline
\end{tabular}

CDE : Continued Dental Education

Table 5. General dental practitioners' responses regarding updating their knowledge of biopsy procedures. 
of electronic mail (7), postal (2) or phone interviews (2). Of the total questionnaires answered, none had to be discarded due to incomplete answers $(<50 \%$ being the criteria) or as a result of lack of understanding or imprecise answers.

The first question ventured to evaluate the importance of biopsy for GDP and it was reassuring to note that all the dentists felt that it was very important to perform a biopsy for diagnosis of lesions.

Regarding the lesions which require biopsy according to their knowledge surprisingly, $4.48 \%$ believed that it should be done only for benign lesions. This belief demonstrates the ignorance of the dentist regarding the significance of detection of premalignant and malignant lesions which could adversely affect the patient health. Though, it was encouraging that $22.38 \%$ knew its right indications.

It is seen from the results that the whole range of benign, malignant, premalignant, cysts have been encountered by the GDPs. This emphasizes the accessibility of GDP to a patient and his important role in diagnosis of oral lesions. It demonstrates how important it is for a GDP to have sufficient knowledge regarding oral pathology and their diagnosis thereof, the lack of which could lead to misdiagnosis and prove detrimental to the patient's wellbeing.

It was observed that $68.6 \%$ of GDPs come across lesions requiring biopsy once a year which was similar to GDPs in Brisbane (63.6\%). Additionally, 3\% answered that they came across such lesions once a week, which was not seen in the Brisbane study (10).

In this study, $14.93 \%$ respondents perform biopsies on their own, which is commendable. This was in accordance to reports by Cowan et al. (13) who reported $12 \%$ in Northern Ireland and $15 \%$ by Diamanti et al. (6) in Manchester. Moreover, Warnakulasuriya and Johnson (14) found that $21 \%$ of dentists in United Kingdom and Seoane et al. (15) reported $24.5 \%$ GDP's perform biopsies in Northwest Spain. In Norway, Berge (16) found that $56 \%$ of dentists attempted biopsy.

Our results also clearly revealed that most of the dentists $(64.67 \%)$ either call a specialist or refer the patient to a higher centre. This was similar to reports by Wan and Savage (10) in Brisbane, where it was seen that $76.2 \%$ of GDPs refer the biopsy cases to a specialist. This could be attributed to several factors like fear of medico-legal complications, unfamiliarity to biopsy technique, lack of faith in personal diagnostic skills, misconception that it is a specialist procedures or concern that if the lesion is malignant, the GDP may not be equipped to inform the patient that he has cancer.

Regarding, how often they refer/ perform biopsies, most answered [38] that they did so at least once a year. This number was less than what was answered for how often lesions were encountered [46]. This is detrimental as it reveals that the dentist even after knowing that the patient has a lesion did not refer/ perform biopsy. Failure to biopsy may lead to persistence of a misdiagnosed malignant lesion or other serious pathology, resulting in an unfavourable downstream course for the patient. It is also demonstrable of negligence on the part of GDP which could even predispose them for a medico legal action.

Moreover, on asking about awareness about excisional, incisional and FNA types of biopsies, majority [40] knew all the methods for biopsy. The rest were aware of only one or other of the biopsy techniques. This explains the need for the GDP to be more congruent with biopsy techniques and their indications and contraindications. This would assist them to decide on the type of biopsy required in individual cases.

It is made known by our study that a total of $25.37 \%$ dentists send the specimens for analysis only when required or sometimes. The rationale for the latter is bit difficult to understand because if they are not intending to send it for analysis; this could point to an uncomfortable trend on causing unnecessary trauma to the patient both physically and monetarily. On the other hand their biopsies may be of benign lesions like mucocele, periapical granuloma; fibrous hyperplasia which is usually apparent on clinical grounds and the biopsy could be as a part of treatment for excising the lesion, so the clinician did not feel the need to send it for analysis.

Regarding, the preservation of the specimen after removal and before sending for analysis, $36(53.73 \%)$ practitioners, rightly knew that it needs to be sent in formalin; while an appalling $20(29.85 \%)$ believed that it needs to be sent in saline and small percentage (11.94\%) thought that it needs to be sent in alcohol; while 2 did not know at all regarding the preservation. This is an important aspect in biopsy that the clinicians often tend to ignore. If the tissue is not preserved properly, it produces lot of artefacts which prevents the pathologist from giving an appropriate diagnosis (17-19). This actually eliminates the rationale of doing biopsy in the first place and may predispose the clinician for undertaking another biopsy further increasing the trauma to the patient.

On asking, how they preserved specimens in their clinic, only 33 said they preserved in formalin while 21 used saline. The dentists who knew that it has to be stored in formalin also tended to send it in alcohol or saline. This could be attributed to negligence, or probably the dentists do not have the formalin in their clinics always since they seldom encounter lesions requiring biopsy. However, the GDP could plan the procedure appropriately and request the pathological laboratory or higher centre to send some bottles filled with formalin for the purpose of preservation. This precaution would benefit the GDP; since the efforts taken in convincing the patient for biopsy and the trauma of the procedure may go 
in vain if the pathologist cannot give a diagnosis due to improper preservation of the tissues.

Since, a large percentage of GDPs did not undertake biopsy; the reasons for this were sought for. There were several answers ranging from lack of experience, lack of instrumentation for biopsy to lack of nearby pathology laboratory. However, the major reasons were that patients do not agree (23.88\%) and lack of experience $(22.39 \%)$ in performing the biopsy by the GDP. The reason most patients do not agree could be the dread/ fear that the report may bring bad news. However, this problem could be resolved by explaining the patient regarding the lesion and the important benefits of early diagnosis. The lack of experience in performing a biopsy by a GDP could be attributed, in part to the lack of importance on practical teaching of biopsy techniques during their training. In fact, there is no such emphasis given in this aspect in the current curriculum of Dental Council of India for the Bachelor of dental surgery degree (20). Further, this aspect was also noticed by Wan and Savage (10), where they said that $58.1 \%$ of GDPs did not feel competent to undertake any biopsies mainly due to lack of experience and practical skills. Diamanti et al. (6) reported $25 \%$ of GDP's surveyed did not feel competent to perform biopsies while Greenwood et al. (21) found that only $21 \%$ of GDPs were prepared to carry out biopsies. These authors felt that the limited use of biopsy procedures is mainly due to inadequate education in these areas and therefore, GDPs who had been taught to biopsy and actually performed a biopsy during their undergraduate studies were more likely to undertake these procedures in general practise.

Thus, 64 dentists in our study too felt the need to update their knowledge regarding biopsy procedures and 62 actually venture to do so by various methods like internet, journals, by discussion with their colleagues etc., which is commendable and reflects that the private dental practitioners are interested in their patients' welfare.

With the exponential growth of dental science, dentists need to update their practices according to the best available scientific evidences. Dentists' treatment decisions are influenced by their knowledge of and attitudes towards care options, and evaluating these is valuable (22).

The results of the study thus show that majority of GDP's do recognise the importance of biopsy procedures in the diagnosis of oral lesions but most still do not perform the biopsies on their own. This was mainly due to inadequate experience and education regarding the same which emphasizes the need for higher levels of importance to be placed on this aspect in undergraduate and postgraduate dental curriculum. Organisation of specific training or continuing dental education programmes regarding biopsy procedures to provide dental practitioners with the experience and practical skills necessary to carry out these procedures safely and confidently.

\section{References}

1. Mota-Ramírez A, Silvestre FJ, Simó JM. Oral biopsy in dental practice. Med Oral Patol Oral Cir Bucal. 2007; 12: E504-10.

2. López Jornet P, Velandrino Nicolás A, Martínez Beneyto Y, Fernández Soria M. Attitude towards oral biopsy among general dentists in Murcia. Med Oral Patol Oral Cir Bucal. 2007;12: E116-21

3. Fedele S. Diagnostic aids in the screening of oral cancer. Head Neck Oncol. 2009;1:5.

4. Jephcott A. The surgical management of the oral soft tissues: 3 . Biopsy. Dent Update. 2007; 34: 654-7

5. Oliver RJ, Sloan P, Pemberton MN. Oral biopsies: methods and applications. BrDentJ.2004; 196: 329-33.

6. Diamanti N, Duxbury AJ, Ariyaratnam S, Macfarlane TV. Attitudes to biopsy procedures in general dental practice. Br Dent J.2002; 192: 588-92.

7. López-Jornet P, Camacho-Alonso F, Molina-Miñano F. Knowledge and attitudes about oral cancer among dentists in Spain. J Eval Clin Pract. 2010; 16:129-33.

8. Franklin G, Jones AV. A survey of oral and maxillofacial pathology specimens submitted by general dental practitioners over a 30 year period. Br Dent J.2006; 200: 447-50.

9. McWilliam LJ, Knox F, Wilkinson N, Oogarah P. Performance of skin biopsies by general practitioners. BMJ. 1991; 303: 1177-9.

10. Wan A, Savage NW. Biopsy and diagnostic histopathology in dental practice in Brisbane: usage patterns and perception of usefulness. Aust Dent J. 2010; 55 : 162-9.

11. Boyle PE. Who should take the biopsy? Oral Surg Oral Med Oral Pathol. 1955; 8:118-22.

12. Porter SR, Scully C. Early detection of oral cancer in the practice. Br Dent J.1998;185:72-3.

13. Cowan CG, Gregg TA, Kee F. Prevention and detection of oral cancer: the views of primary care dentists in Northern Ireland. $\mathrm{Br}$ Dent J. 1995;179: 338-42.

14. Warnakulasuriya KA, Johnson NW. Dentists and oral cancer prevention in the UK: opinions, attitudes and practices to screening for mucosal lesions and to counselling patients on tobacco and alcohol use: baseline data from 1991. Oral Dis. 1999; 5: 10-4.

15. Seoane J, Valera-Centelles PI, Ramírez JR, Cameselle-Teijeiro J, Romero MA. Artifacts in oral incisional biopsies in general dental practice: a pathology audit. Oral Dis. 2004; 10:113-7

16. Berge TI. Oral surgery in Norwegian general dental practice--a survey. Extent, scope, referrals, emergencies, and medically compromised patients. Acta Odontol Scand. 1992; 50 :7-16.

17. Margarone JE, Natiella JR, Vaughan CD. Artefacts in oral biopsy specimens. J Oral Maxillofac Surg. 1985;43: 163-72.

18. Moule I, Parsons PA, Irvine GH. Avoiding artefacts in oral biopsies: the punch biopsy versus the incisional biopsy. Br J Oral Maxillofac Surg. 1995;33: 244-7.

19. Ficarra G, McClintock B, Hansen LS. Artefacts created during oral biopsy procedures. J Craniomaxillofac Surg. 1987;15: 34-7

20. Dental Council of India (Internet) India : BDS course regulation 2007 (Cited 2010 aug 28) Available from http//: www.dciindia. org/ dci regulation_2006_pages/BDS_course_regulation.html

21. Greenwood LF, Lewis DW, Burgess $\overline{R C}$. How competent do our graduates feel? J Dent Educ.1998; 62: 307-13.

22. Ghasemi H, Murtomaa H, Torabzadeh H, Vehkalahti MM. Knowledge and Attitude towards Preventive Dental Care among Iranian Dentists. Eur J Dent. 2007;1: 222-9. 